\title{
Needle Damage Development in Norway Spruce Seedlings as Affected by Humidity, Temperature, and Gray Mold: A Preliminary Study
}

\author{
Raija-Liisa Petäistö and Juha Heiskanen \\ Suonenjoki Unit, Finnish Forest Research Institute, 77600 Suonenjoki, Finland \\ Correspondence should be addressed to Raija-Liisa Petäistö, raija-liisa.petaisto@metla.fi
}

Received 30 April 2012; Accepted 4 June 2012

Academic Editors: A. Santini, A. Scariot, and P. Smethurst

Copyright ( $) 2012$ R.-L. Petäistö and J. Heiskanen. This is an open access article distributed under the Creative Commons Attribution License, which permits unrestricted use, distribution, and reproduction in any medium, provided the original work is properly cited.

\begin{abstract}
Botrytis cinerea inoculation on 3- and 6-month-old Norway spruce seedlings was tested in combinations of temperature (15 and $25^{\circ} \mathrm{C}$ ) and relative humidity (50 and 80\%) in a growth chamber. Occurrence of needle damage was examined 11 days after the inoculation. Damage occurred more on inoculated than on control seedlings. Needle damage tended to occur proportionally more on the older seedlings and concentrating more on the tops of the shoot in the younger seedlings. The higher temperature suggested slightly more damage occurrence than the lower temperature did. The relative humidity did not appear to correlate with the damage outbreak. Surface wetness tended to increase the damage occurrence but so did also the vapour pressure deficit. At the lower relative humidity, the seedlings had to be irrigated more frequently, which increased the surface wetness. Thus, the results suggest that any irrigation method or other condition control that can provide low surface wetness on seedlings decreases needle damage by $B$. cinerea in forest nurseries.
\end{abstract}

\section{Introduction}

The gray mold fungus (Botrytis cinerea Pers.: Fr.) is a facultative parasite. It lives as a saprophyte on dead plant material and is also a plant pathogen. The temperature optimum for gray mold spore germination and infection is $9-21^{\circ} \mathrm{C}$, but temperatures between $2-25^{\circ} \mathrm{C}$ are also suitable for the fungus [1-4]. Relative humidity greater than $98 \%$ and free water are optimal for spore germination and mycelia growth of the $B$. cinerea fungus, for example, [5].

In Finland, Norway spruce (Picea abies (L.) Karst.) is the predominant species in forest nursery seedling production. In recent decades, container seedling production has increased and there has also been a subsequent increase in damage caused by gray mold $[6,7]$. This increase is partly due to higher seedling densities and to microclimatic conditions, which differ from those in bare root seedling production. The damage may occur only few days after inoculation on vital needles [8]. Visual symptoms are spots of discoloration usually in the middle of the needles or completely dead needles [8].
Numerous studies have been carried out on gray mold on agricultural crops, while fewer studies have dealt with gray mold on conifer seedlings, for example, Picea mariana (Mill.) B.S.P, [9, 10], Sequoiadendron giganteum (Lindl.) Dene [11], Pseudotsuga menziesii (Mirb.) Franco [5] 1988, and Larix occidentalis (Nuttall) [12]. In the nursery, gray mold development is known to be dependent on the growth phase of the seedlings [8] but also markedly on the ambient microclimate [13], effect of which is not studied much with Norway spruce so far.

The aim of this study was to survey the effects of relative humidity and temperature and Botrytis cinerea inoculation on needle damage outbreak on first-year Norway spruce seedlings in the middle and at the end of the growing season. Bioassays were conducted in growth chambers.

\section{Materials and Methods}

2.1. Seedling Material. The first seedling set (set 1) was sown using seeds of regional origin in a growth chamber 
on 5th October and the second one (set 2) on 18th October 2001 in PL-81F containers $\left(85 \mathrm{~cm}^{3}\right.$ container size, 81 containers per tray, seedling density $546 \mathrm{~m}^{-2}$ ) (BCC Oy, Lannen Plant Systems, Säkylä, Finland) filled with low-humified sphagnum peat. Seedlings were grown using normal growing procedures as in tree nurseries [14]. The use of more than one seedling set was necessary because only two smaller growth chambers (i.e., two temperature/relative humidity combinations from the wanted four combinations) were available simultaneously for condition treatments at the same age of seedlings.

Both seedling sets were grown in a bigger growth chamber (Type 10'Sp/5 DU-Pi, Weiss Umwelttechnik, Lindenstruth, Germany) before moving them into smaller growth chambers with different treatment conditions. In the bigger growth chamber, photosynthetically active radiation at the seedling shoot level was $300-400 \mu \mathrm{E} \mathrm{m}^{-2} \mathrm{~s}^{-1}$ (about onethird or half of full day light) and temperature varied during the day and night from 15.5 to $19.0^{\circ} \mathrm{C}$, and the relative humidity $80-95 \%$. The day and night rhythm was simulated to correspond to the natural growing season, which meant decreased temperature and increased relative humidity during the night.

To confirm that growth rhythm of the seedling sets differed or not from each other, seedling height (Figure 1(a)) was measured weekly on 4 random trays (from 8 seedlings per tray) from the seedling sets 1 and 2. Seedling height and the number of needles were measured at the age of 3 and of 6 months on 4 trays (from 5 seedlings per tray) of the seedling set 1 . At the seedling age of 3 months, the mean value (4 trays, 5 seedlings per tray) of the total number of needles per seedling was 358.7 ( $s d 53.38$ ), and the mean height of the measured seedlings $131.6 \mathrm{~mm}$ (sd 24.75). The corresponding values at the age of 6 months were 383.2 (sd 32.06) and $140.1 \mathrm{~mm}$ (sd 18.16). On the basis of these data, the mean number of needles was estimated from the seedling heights $\left(y=230.52+1.02 *\right.$ height, $\left.R^{2}=0.09, P=0.019\right)$ and was used for seedlings from the seedling sets 1 and 2 .

In addition, seedlings sown on 22nd April 2002 (set 3 ) in a production greenhouse of the Suonenjoki Research Unit were used at age of 5 months and 9 days and 5 months and 24 days (handled as one age group). The height of these seedlings was measured every second week during the growing season on 4 trays (from 9 seedlings per tray) (Figure 1(b)). The number of needles per seedling was measured at an age of about 6 months on 4 trays (from 5 seedlings per tray). The mean number of needles was 740 per seedling (sd 77.26) and the mean height of the seedlings was $193 \mathrm{~mm}$ (sd 34.75). The number 740 was subsequently used as an estimate for the total number of needles/seedling for these seedlings. In all the seedling sets, the height growth stopped at the age of $4.5-5$ months (Figures $1(\mathrm{a})$ and $1(\mathrm{~b})$ ).

2.2. Inoculation. Gray mold isolate BcSjk1.1 is a monospore culture, originating from a diseased spruce seedling from Suonenjoki in 1998. The isolate was stored in a deep freezer as mycelium in cryoprotectant (sterile glycerol and phosphate buffered saline, $1: 4)$. For spore production, the isolate was grown on potato dextrose agar medium for 3 days at $17^{\circ} \mathrm{C}$ in the dark, then for 3 days at $17^{\circ} \mathrm{C}$ in the light, and finally stored at $4^{\circ} \mathrm{C}$ until needed. The spores were liberated by pipetting sterile water onto the fungal culture and brushing the culture with a glass rod. The water was then filtered through double gauze to eliminate mycelial fractions. For the inoculations, the spore suspension was diluted to $1 \times$ $10^{6}$ spores per $\mathrm{mL}$.

The inoculation was made when the seedlings were about 3- and 6-month old (Table 1). The first 4 rows of seedlings in each tray were inoculated ( 9 seedlings per row), and the seedlings in the last 4 rows were used as a control. The fifth seedling row, that is, the row lying between four inoculated rows and four uninoculated (control) rows acted as a buffer zone.

A plastic bottle with the bottom removed was placed over the seedling to be inoculated. $3.2 \mathrm{~mL}$ of spore suspension $(1 \times$ $10^{6}$ spores per $\mathrm{mL}$ ) was sprayed onto each seedling (sprayer Birchmeier, Fuxy, Switzerland). The control seedlings were sprayed with water. The surface of the growth medium was covered with a water-absorbing towel layer during inoculation in order to prevent the spore suspension from infiltrating into the peat.

The inoculated and control seedlings were examined visually every second day for 11 days after inoculation. The damages were colour-changed spots on needles or completely dead needles [8]. The number and position of needles with symptoms were recorded on each seedling. Level of the damage was calculated as a percentage of damaged needles per seedling.

2.3. Microclimatic Treatments. After inoculation, the seedlings were exposed to the treatments in the two smaller growth chambers (Weiss Umwelttechnik, Type 1600 $\mathrm{Sp} /+5 \cdots+45 \mathrm{DU}-\mathrm{Pa}$ ), where the day length, temperature, and relative humidity were regulated. There were four trays (set 1 and set 3 ) or three (set 2) trays (81 seedlings per tray) for each treatment $*$ age combination (Table 1). For the seedling set 1 , the treatments were $25^{\circ} \mathrm{C} / 80 \mathrm{RH}$, and $25^{\circ} \mathrm{C} / 50 \mathrm{RH}$, and seedling age 3 and 6 months. For the seedling set 2 , the treatments were $15^{\circ} \mathrm{C} / 80 \mathrm{RH}$ and $15^{\circ} \mathrm{C} / 50$ $\mathrm{RH}$ at seedling age 3 and 6 months. For the seedling set 3 , the treatments were $25^{\circ} \mathrm{C} / 80 \mathrm{RH}, 25^{\circ} \mathrm{C} / 50 \mathrm{RH}, 15^{\circ} \mathrm{C} / 80$ $\mathrm{RH}$, and $15^{\circ} \mathrm{C} / 50 \mathrm{RH}$ at seedling age 5.3-5.8 months (age handled as one age group). In the treatments, temperature actually fluctuated within $25-30(25)$ and $14-19^{\circ} \mathrm{C}(15)$, and the relative humidity within $80-98$ (80) and $37-55 \%$ (50) (Table 1).

Air temperature, light intensity, relative humidity, and surface wetness were measured with sensors placed about $2 \mathrm{~cm}$ above the peat medium. Vapour pressure deficit was calculated from temperature and humidity. Air temperature and relative humidity were measured with HMP $133 \mathrm{Y}$ sensors (Vaisala, Helsinki, Finland), light intensity with LI190SZ quantum sensors (LI-COR, Lincoln, Nebraska, USA), and surface wetness with Delta-T Devices sensors (Delta$\mathrm{T}$ Devices, Cambridge, England). Temperature, relative humidity, and surface wetness sensors were connected to a 


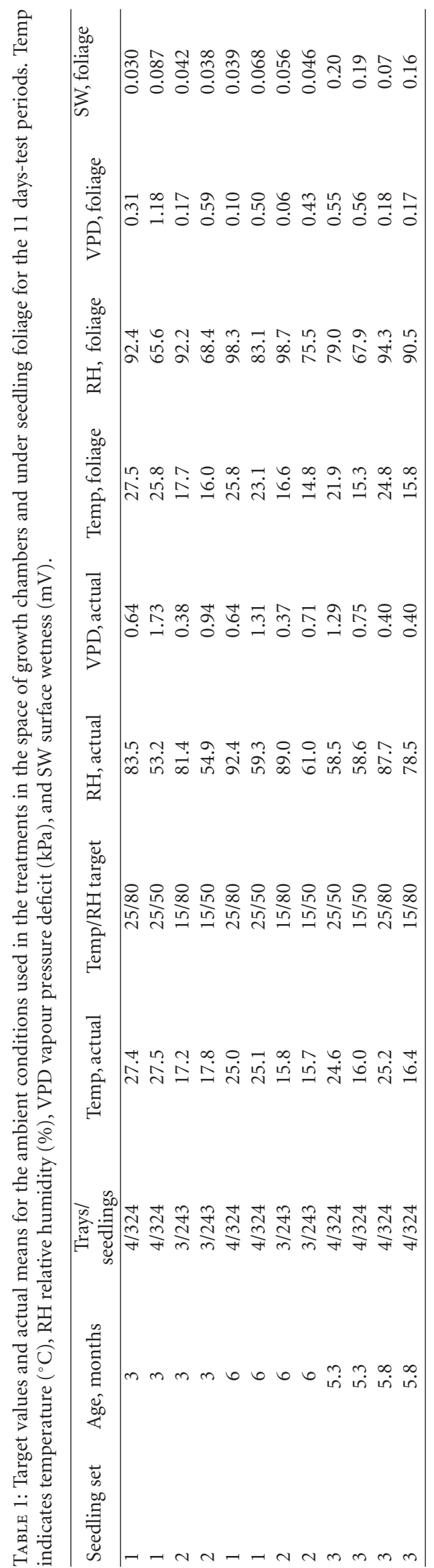




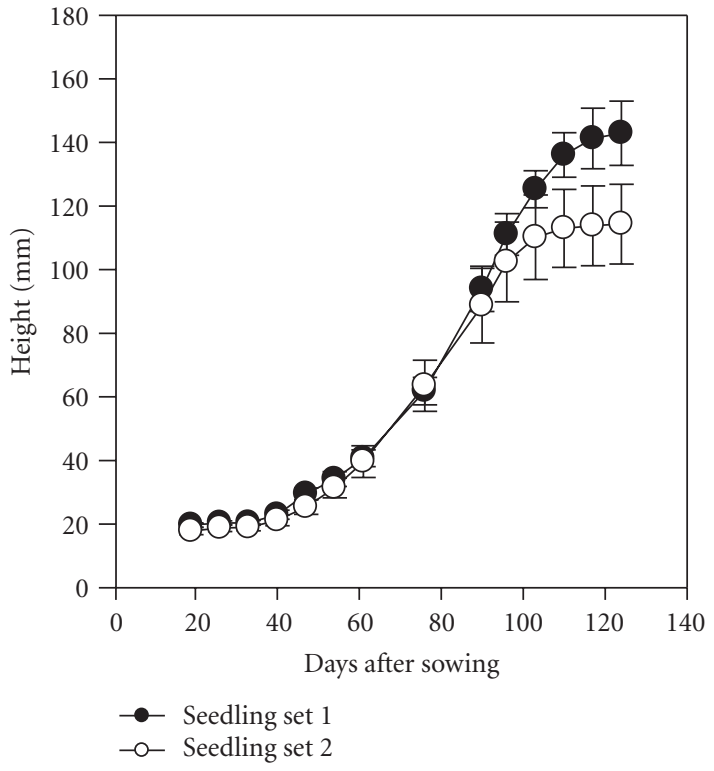

(a)

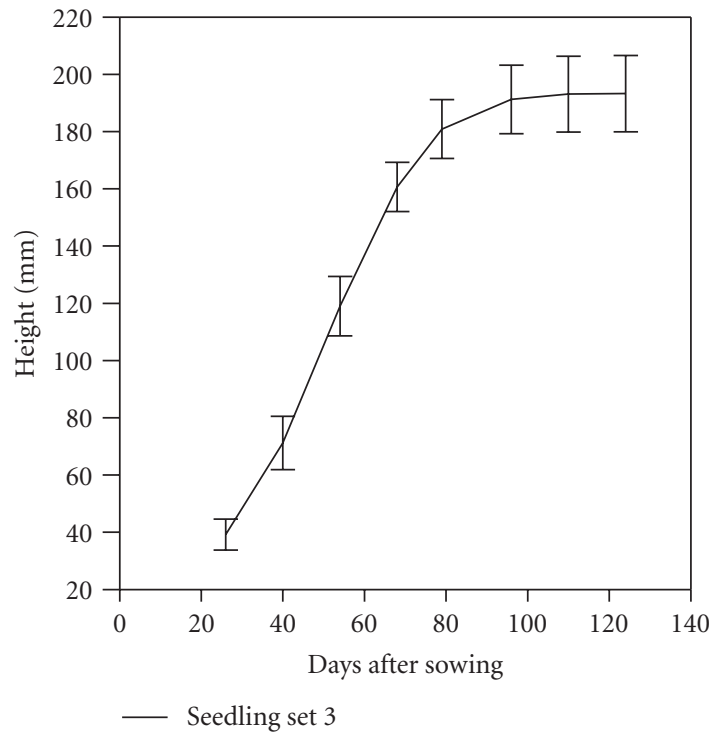

(b)

Figure 1: (a) Height development in the seedling sets $1(\bullet)$ and 2 (o). (b) The height development in the seedling set 3.

Campbell data logger (CR10X, Campbell Scientific, Loughborough, England), which was set to retrieve data every 5 minutes.

2.4. Data Analysis. The number of needles infected by gray mold was calculated per seedling and used as the number or as the percentage of the total estimated needle number per seedling at a given growth stage. The trays for each treatment were completely randomized. The data analysis was done within each seedling set. Different seedling sets with different temperature and humidity combinations were used because there were only two growing chambers simultaneously. GLM univariate ANOVA procedure and Tukey's test in the statistical software SPSS 11 were used. Condition treatment, inoculation, and seedling age were used as fixed factors and tray as a random factor. Prior to ANOVA, arcsin transformation was not needed for percentage values because the total number of needles was much greater than the number of needles infected. Also the number of seedlings was large enough.

\section{Results}

The proportion of damaged needles was not significantly affected by treatments $25 / 80$ and $25 / 50$, but it was affected by inoculation $(P<0.001)$ and age of seedling $(P<0.001)$ in seedling set 1 . The damage proportion was bigger in inoculated seedlings than in control and bigger at age of 6 months than at age of 3 months of seedlings (Table 2(a), Figure 2). At seedling age of 6 months with treatment 25/50 and at the seedling age of 3 months with treatment $25 / 80$, the inoculation increased needle damage most clearly.
The percentage of damaged needles was also not affected by the treatments $15 / 80$ and $15 / 50$ (seedling set 2 ) but affected by inoculation $(P<0.001)$ and also by age $(P<0.01)$, older seedlings were more damaged (Table 2(b), Figure 2).

Treatments $(25 / 50,15 / 50,25 / 80$, and $15 / 80$, seedling set 3$)$ affected significantly $(P<0.001)$ and inoculation increased the needle damage (Table 2(c), Figure 2). Differences were found between treatments 25/50 and 15/50 $(P<0.05)$, but not between treatments $25 / 80$ and $15 / 80$. In treatment $25 / 50$, the damage percentage was higher and it differed from all the other treatments $(25 / 80,15 / 50,15 / 80)$ $(P<0.003)$ (Figure 2).

The percentage of damage needles increased almost linearly during the 11-day period (Figure 2 ). In the case of inoculated 3- and 6-month-old seedlings, about 40-50 and $20 \%$ of all the damaged needles, respectively, were situated at the top of seedlings in seedling sets 1 and 2 (Figure 3 ).

In treatments with seedling sets 1 and 2 , the temperature of $25^{\circ} \mathrm{C}$ was somewhat more favorable for damage occurrence than the temperature of $15^{\circ} \mathrm{C}$ (Figure 4). The relative humidity (53-92\%) did not appear to be correlated with outbreak of the damage (Figure 4). Surface wetness related positively to the damage occurrence, as was the case also for vapour pressure deficit (Figure 4). The effect seemed to be clearer on 6-month-old than on 3-month-old seedlings. The surface wetness at an age of 3 months was in fact higher than those shown, while the sensors did not timely contact with the irrigation water. Furthermore, relative humidity measured within the seedling canopy in the growth chamber differed from those outside the canopy relative humidity was $6-24 \%$ units greater within the seedling canopy.

The relationships between the proportion of damaged needles and the ambient conditions in noninoculated 

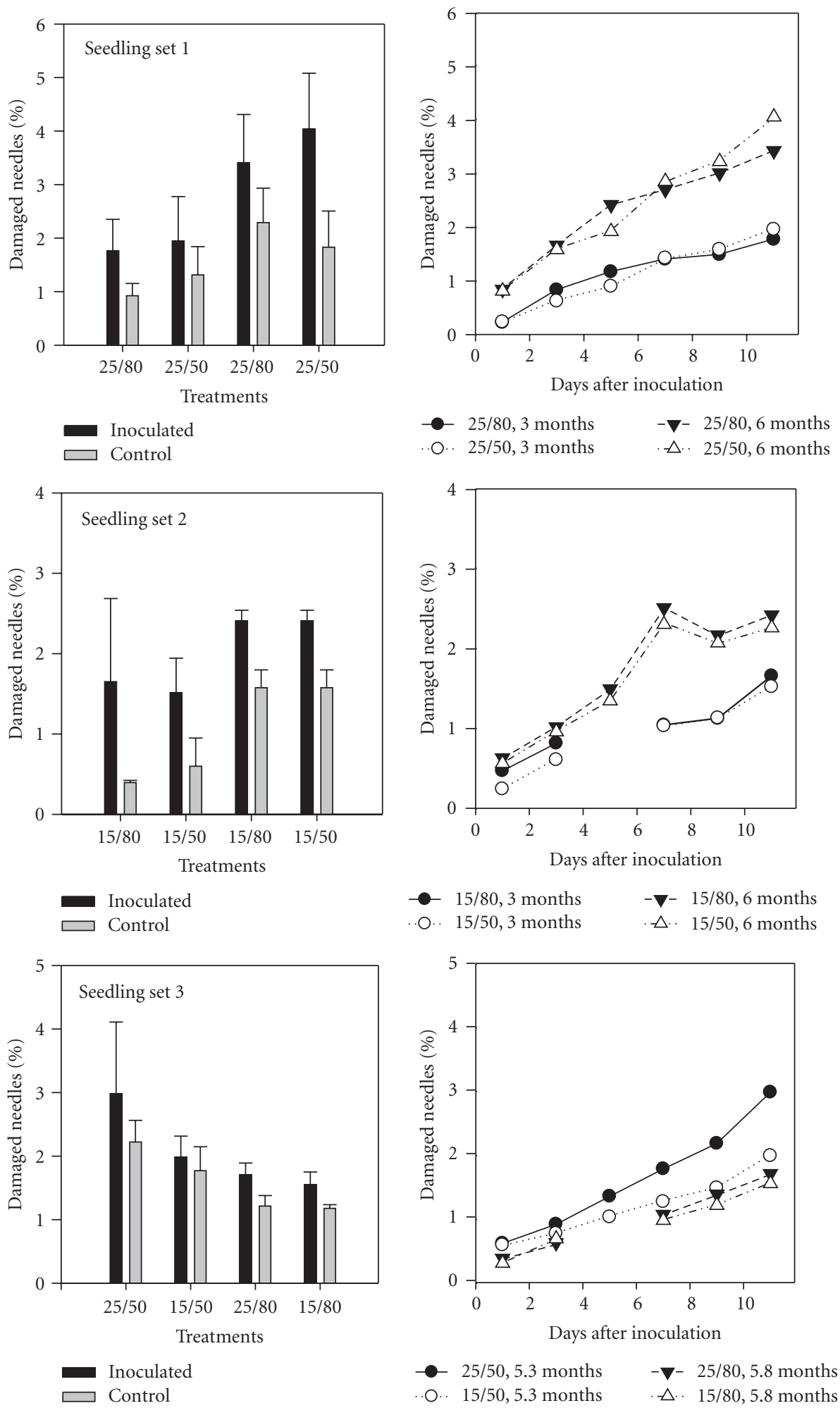

(a)

(b)

FIGURE 2: (a) The percentage of damaged needles on the inoculated and control seedlings as mean of tray means. In the seedling sets 1 and 2 , the first two group bars denote 3-month-old seedlings and the second two group bars 6-month-old seedlings. In seedling set 3, the seedlings were 5.3 and 5.8 months old. (b) The percentage of damaged needles on inoculated seedlings 1-11 days after inoculation. 
TABLE 2: Univariate analysis results for the effects of treatment, age, and inoculation on the percentage of damaged needles per seedling (a) in seedling set 1 , treatments $25 / 80$ and $25 / 50$ to 3 - and 6-monthold seedlings. (b) In seedling set 2, treatments $15 / 80$ and 15/50 to 3and 6-month-old seedlings. (c) In seedling set 3, treatments 25/50, $15 / 50,25 / 80$, and $15 / 80$ to 5.3 - and 5.8-month-old seedlings.

(a)

\begin{tabular}{lcccc}
\hline Source & $d f$ & MS & $F$ & $P$ \\
\hline Intercept & 1 & 153.27 & 167.44 & 0.000 \\
Inoculation & 1 & 11.50 & 95.92 & 0.000 \\
Age & 1 & 15.80 & 17.26 & 0.001 \\
Treatment & 1 & 0.27 & 0.30 & 0.595 \\
Inoculation $*$ age $*$ treatment & 1 & 0.83 & 6.96 & 0.022 \\
Inoculation $*$ age & 1 & 1.71 & 14.27 & 0.003 \\
Inoculation $*$ treatment & 1 & 0.39 & 3.25 & 0.097 \\
Age $*$ treatment & 1 & 0.08 & 0.09 & 0.769 \\
Age $*$ treatment $*$ tray & 12 & 0.915 & 7.64 & 0.001 \\
\hline
\end{tabular}

(b)

\begin{tabular}{lcccc}
\hline Source & $d f$ & MS & $F$ & $P$ \\
\hline Intercept & 1 & 53.97 & 120.13 & 0.000 \\
Treatment & 1 & 0.00 & 0.00 & 0.957 \\
Age & 1 & 5.09 & 11.33 & 0.010 \\
Inoculation & 1 & 4.99 & 34.59 & 0.000 \\
Treatment $*$ age $*$ inoculation & 1 & 0.01 & 0.06 & 0.815 \\
Treatment $*$ age & 1 & 0.02 & 0.03 & 0.859 \\
Treatment $*$ inoculation & 1 & 0.11 & 0.73 & 0.419 \\
Age $*$ inoculation & 1 & 0.18 & 1.24 & 0.298 \\
Age $*$ treatment $*$ tray & 8 & 0.45 & 3.12 & 0.064 \\
\hline
\end{tabular}

(c)

\begin{tabular}{lcccc}
\hline Source & $d f$ & MS & $F$ & $P$ \\
\hline Intercept & 1 & 106.576 & 538.389 & 0.000 \\
Treatment & 3 & 2.535 & 12.806 & 0.000 \\
Inoculation & 1 & 1.682 & 6.994 & 0.021 \\
Treatment $*$ inoculation & 3 & 0.105 & 0.437 & 0.730 \\
Treatment $*$ tray & 12 & 0.198 & 0.823 & 0.629 \\
\hline
\end{tabular}

seedlings were similar to those in the inoculated seedlings (Figure 4), but with slightly smaller proportion of damaged needles (Figure 2).

In treatments with seedling set 3 , the mean relative humidity was $59-88 \%$ (Table 1, Figure 4 ). The surface wetness showed a positive correlation with the damage occurrence, while relative humidity was negatively correlated. A temperature of $25^{\circ} \mathrm{C}$ was somewhat more favorable for occurrence of the visible damage than a temperature of $15^{\circ} \mathrm{C}$ (Figure 4). Vapour pressure deficit correlated positively with the needle damage.

\section{Discussion}

Botrytis cinerea is a very common fungus also in forest nurseries. The microclimatic conditions prevailing after $B$. cinerea spore infection are important for needle damage

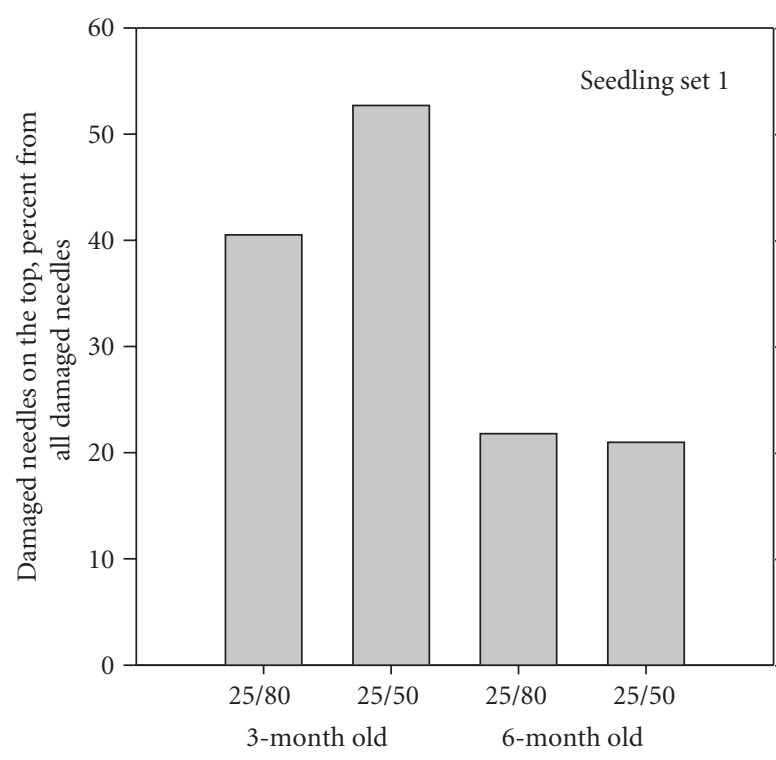

(a)

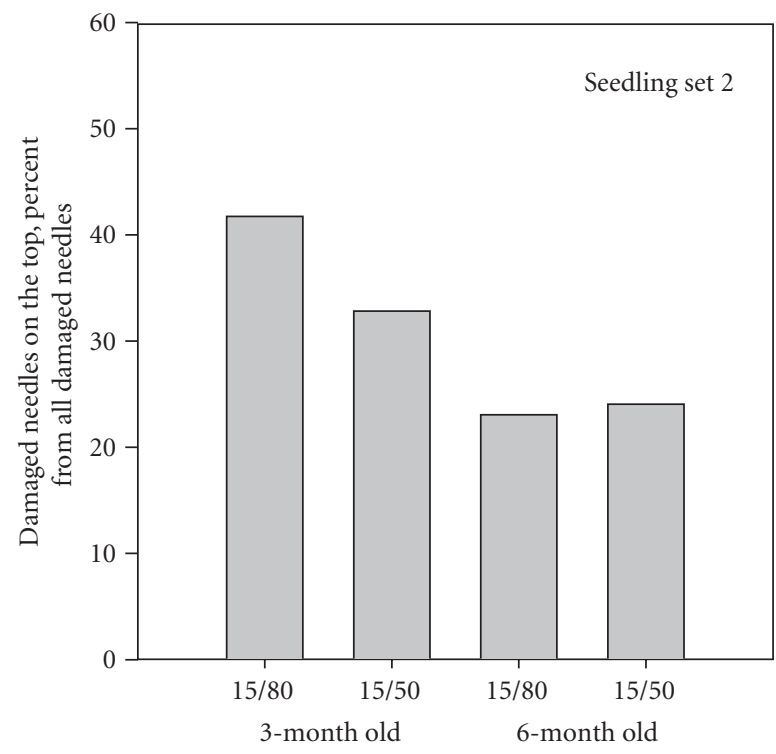

(b)

FIGURE 3: The proportion of damaged needles located on the top of the seedlings at seedling ages of 3 and 6 months.

occurrence, in addition to the susceptible growth phase [8], winter storage [13], and predisposition of seedlings, for example, by drought and shading [10]. During seedling production, spores of the fungus [5] have been found more frequently in tree seedling greenhouses towards the autumn. In the present study, the uninoculated seedlings also bore needle damage but less than the inoculated seedlings. The difference of needle damage frequency between inoculated and uninoculated seedlings obviously means $B$. cinerea successful infection, but it was not verified by reisolations.

In the present study, the temperature of $25^{\circ} \mathrm{C}$ proved to be more favorable than that of $15^{\circ} \mathrm{C}$ for gray mold infection in Norway spruce seedlings. Both these temperatures are 


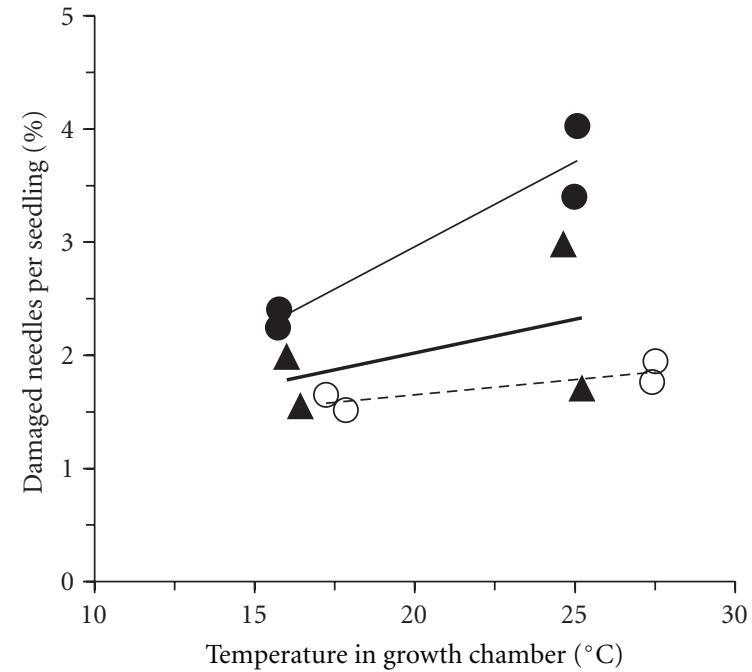

(a)

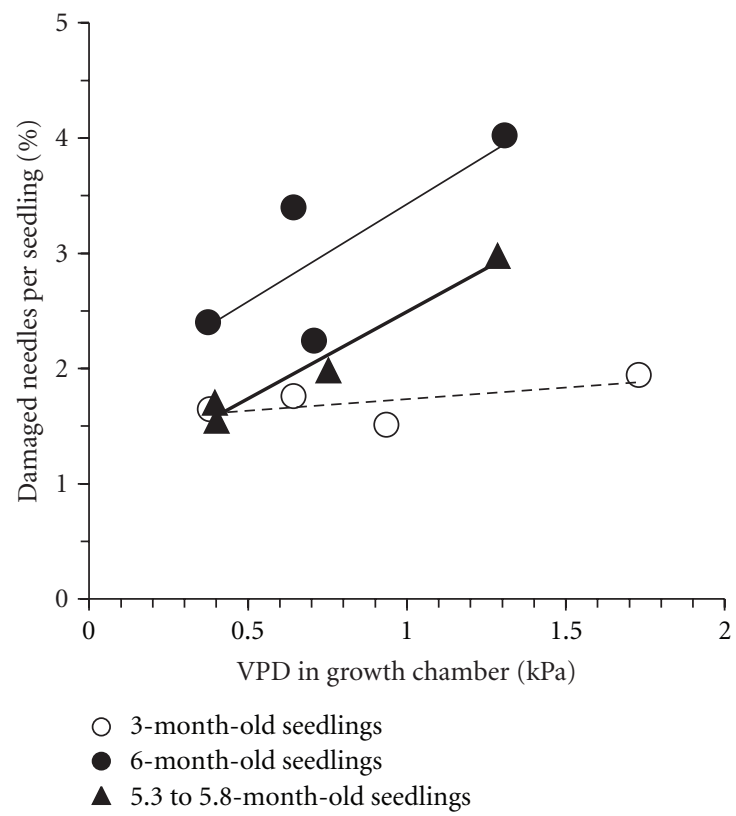

(c)

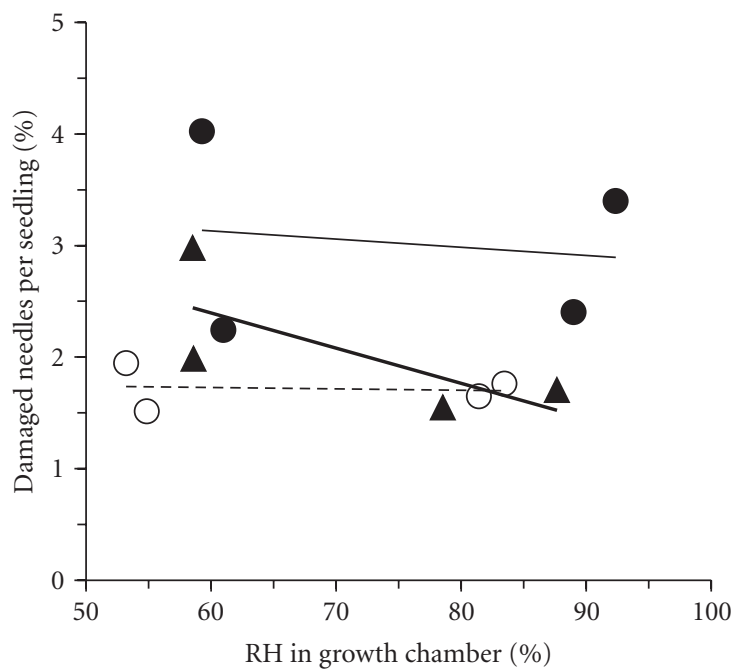

(b)

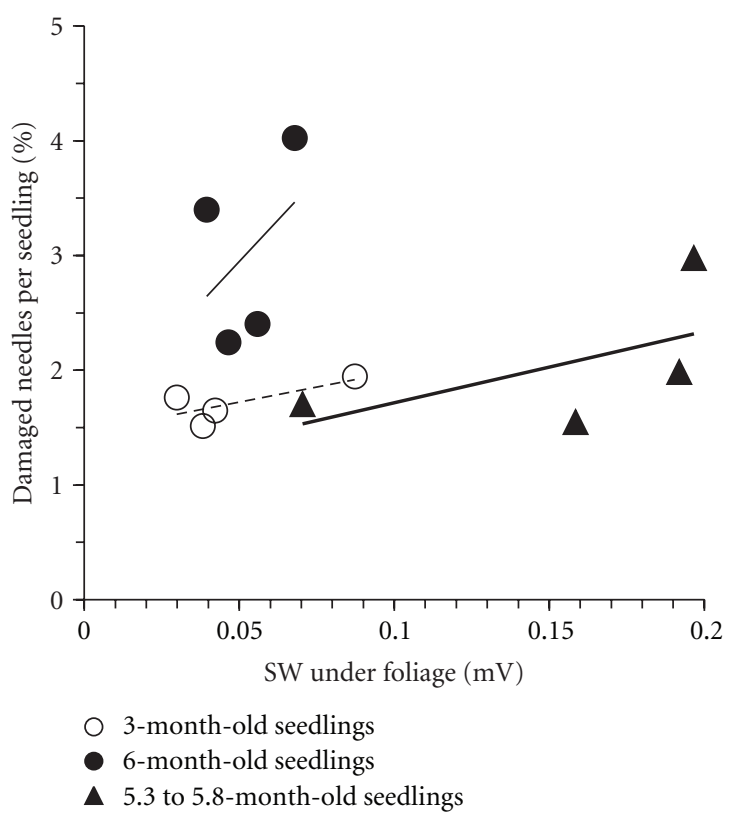

(d)

FIGURE 4: Relationships between temperature, relative humidity (RH), and vapour pressured deficit (VPD) in the growth chamber air space and surface wetness (SW) under the foliage with the percentage of damaged needles 11 days after inoculation in the different treatments with different seedling ages.

close to those reported in the literature for optimum gray mold spore germination and infection in other host plants $10-21^{\circ} \mathrm{C}[2,15], 18-25^{\circ} \mathrm{C}[4], 11-16^{\circ} \mathrm{C}$, or $11-25^{\circ} \mathrm{C}$, depending on the infection phase [16].

The increase in surface wetness tended to increase the occurrence of the damage. When the relative humidity was lower (50\%), the seedlings had to be irrigated more frequently than at higher humidity. The spores require free water for germination and growth. Correspondingly, the contradiction between the effects of a vapour pressure deficit and relative humidity on the level of needle damage is due to the more frequent irrigation under high evapotranspiration conditions. With other hosts, it has been found that the relative humidity must be near to $100 \%$ or water otherwise available (as surface wetness) for $B$. cinerea infection to occur $[4,13,17]$.

In practice, rain and overhead irrigation cause surface wetness on the plant. Our results suggest that the risk of gray mold damage could be reduced by arranging irrigation in such a way that surface wetness does not prevail for a too long period of time. This could be done by choosing an appropriate irrigation system (overhead, drip, or capillary 
irrigation) and/or by adjusting the timing and drop size of irrigation.

In an epidemiological sense, the occasional occurrence of low relative humidity also might have an increasing effect on the disease occurrence, because air-borne spore dispersion is also facilitated at a low relative humidity $[16,18]$. On the other hand, during irrigation, the spore number in the air can increase as a result of the mechanical forces imposed by water drops [5].

The eleven-day follow-up period after inoculation used here might be too short. By extrapolating the results, it can be assumed that the differences between some of the treatments may have increased after 11 days. In addition, a latent period after inoculation is possible $[16,19]$. However, the trends of damage occurrence in the 11-day period after inoculation make it possible to draw some conclusions: a temperature of near $20^{\circ} \mathrm{C}$ and surface wetness are conditions favouring damage occurrence during short periods. The needle damage occurs proportionally more on the tops, which is more harmful [13], of the shoot in three-month-old seedlings than in older seedlings. The height growth of the older seedlings stopped before the inoculation, which most probably is a reason for proportionally less damage on the tops at this age.

In the study of Petäistö et al. [8], the effect of B. cinerea inoculation at the various age of seedlings in greenhouses began to decrease after about 4 months seedling age, but the temperature and VPD values correlated with the seedlings age. This recent study with regulated temperature and humidity gives preliminary information about gray mold and microclimate combinations at various seedling ages. Nowadays, many sowing times may be used during the growing season and so also the seedling growth phases differ more at the same time point/and microclimate condition.

In conclusions, the needle damage by $B$. cinerea occurs proportionally more on the older age of seedlings but more on the tops (youngest parts) of younger seedlings. Surface wetness and higher temperature and higher vapour pressured deficit suggested increased needle damage, and damage was more frequent in inoculated than in control seedlings in this study. Therefore, irrigation methods or other condition controls that can decrease the surface wetness could decrease the needle damage caused by $B$. cinerea in forest nurseries. However, for deriving more conclusive results and implications, larger fully factorial studies in growth chambers and in greenhouses are required in the future.

\section{Acknowledgments}

The authors would like to thank the staff of the Suonenjoki Research Station, especially Eeva Vehviläinen and Jukka Laitinen, for technical assistance. Thanks go to Risto Rikala for comments on the study, to Juha Lappi for comments on the data analysis, and to Marja Poteri for reading and commenting on the paper. The Foundation for Research of Natural Resources in Finland supported the study.

\section{References}

[1] Y. Elad, "Effect of abiotic conditions on development of gray mold of rose and scanning electron microscopy," Phytopathologia Mediterranea, vol. 28, pp. 122-130, 1989.

[2] W. R. Jarvis, Epidemiology. Biology of Botrytis, Academic Press, London, UK, 1980, Edited by: J. R. Coley-Smith, K. Verhoeff and W. R. Jarvis.

[3] J. J. Marois, J. C. Redmond, and J. D. MacDonald, "Quantification of impact of environment on the susceptibility of Rosa hybrida flowers to Botrytis cinerea," Journal of the American Society for Horticultural Science, vol. 113, pp. 842-845, 1988.

[4] J. Salinas, D. C. M. Glandorf, F. D. Picavet, and K. Verhoeff, "Effects of temperature, relative humidity and age of conidia on the incidence of spotting on gerbera flowers caused by Botrytis cinerea," Netherlands Journal of Plant Pathology, vol. 95, no. 1, pp. 51-64, 1989.

[5] M. J. Peterson, J. R. Sutherland, and S. E. Tuller, "Greenhouse environment and epidemiology of grey mould of containergrown Douglas-fir seedlings," Canadian Journal of Forest Research, vol. 18, pp. 974-980, 1988.

[6] M.-L. Juntunen, "Weeds, diseases, insects and mites and use of pesticides in Finnish forest nurseries-result of a survey study," in Proceedings of the 4th Meeting of IUFRO Working Party 7.03.04, A. Lilja and J. R. Sutherland, Eds., Diseases and Insects in Forest Nurseries, Finnish Forest Research Institute, 2000, Research Papers 781:189-200.

[7] C. Nyström and M. Hannerz, "Svensk plantproduction under lupp," Plantaktuell, vol. 1, pp. 4-5, 2002 (Swedish).

[8] R.-L. Petäistö, J. Heiskanen, and A. Pulkkinen, "Susceptibility of Norway spruce seedlings to grey mould in the greenhouse during the first growing season," Scandinavian Journal of Forest Research, vol. 19, no. 1, pp. 30-37, 2004.

[9] P. G. Zhang, J. C. Sutton, B. He, and A. A. Hopkin, "Low light intensity predisposes black spruce seedlings to infection by Botrytis cinerea," Canadian Journal of Plant Pathology, vol. 17, pp. 13-18, 1995.

[10] P. G. Zhang and J. C. Sutton, "High temperature, darkness, and drought predispose black spruce seedlings to gray mold," Canadian Journal of Botany, vol. 72, no. 2, pp. 135-142, 1994.

[11] P. C. Smith, A. H. McCain, and M. D. Srago, "Control of Botrytis storage rot of giant sequoia seedlings," Plant Disease Report, vol. 57, pp. 67-69, 1973.

[12] F. Dugan and G. M. Blake, "Penetration and infection of western larch seedlings by Botrytis cinerea," Canadian Journal of Botany, vol. 67, pp. 2596-2599, 1989.

[13] R.-L. Petäistö, "Botrytis cinerea and Norway spruce seedlings in cold storage," Baltic Forestry, vol. 11, no. 2, pp. 24-33, 2006.

[14] J. Heiskanen, "Effects of compost additive in sphagnum peat growing medium on Norway spruce container seedlings," New Forests. In press.

[15] D. Shtienberg and Y. Elad, "Incorporation of weather forecasting in integrated, biological-chemical management of Botrytis cinerea," Phytopathology, vol. 87, no. 3, pp. 332-340, 1997.

[16] H. Yunis, Y. Elad, and Y. Mahrer, "Effects of air temperature, relative humidity and canopy wetness on gray mold of cucumbers in unheated greenhouses," Phytoparasitica, vol. 18, no. 3, pp. 203-215, 1990.

[17] M. Peterson, "Botscan: a sampling system to forecast disease incidence of grey mould in container-grown conifer seedlings," Nursery and Seed, vol. 1, pp. 9-10, 1995.

[18] W. R. Jarvis, "The dispersal of spores of Botrytis cinerea Fr. In a raspberry plantation," Transactions of the British Mycological Society, vol. 45, pp. 549-559, 1962. 
[19] W. R. Jarvis, "The infection of strawberry and raspberry fruits by Botrytis cinerea Fr.," Annals of Applied Biology, vol. 50, no. 3, pp. 569-575, 1962. 

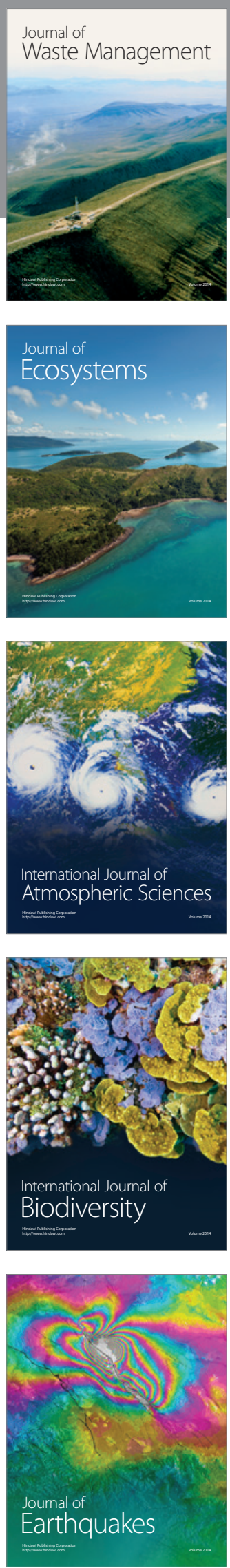
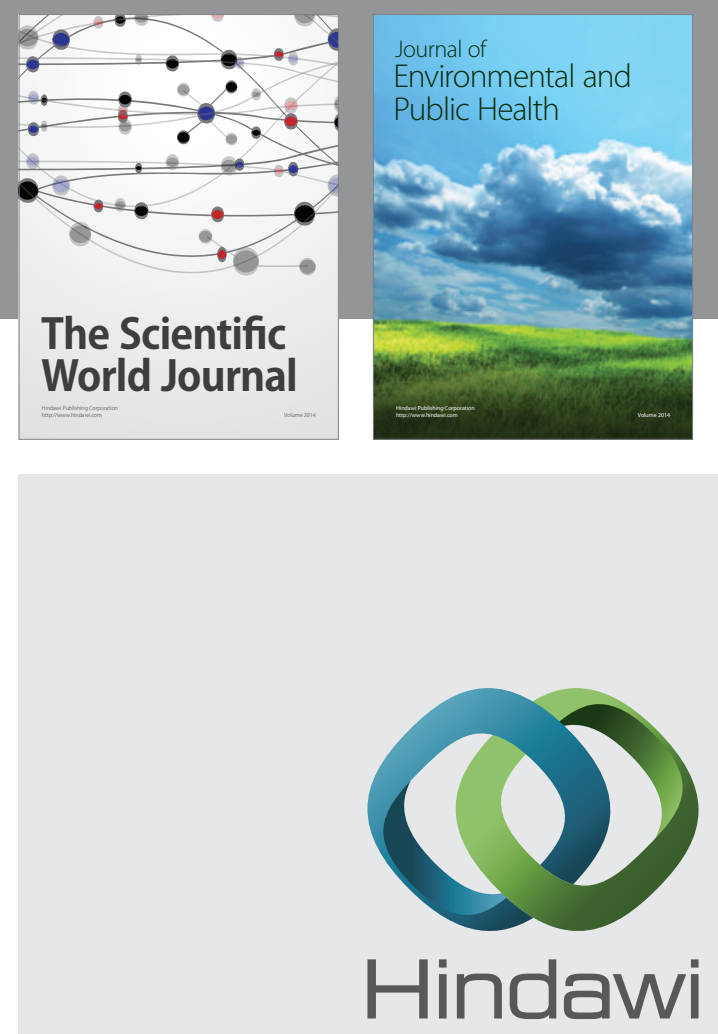

Submit your manuscripts at

http://www.hindawi.com
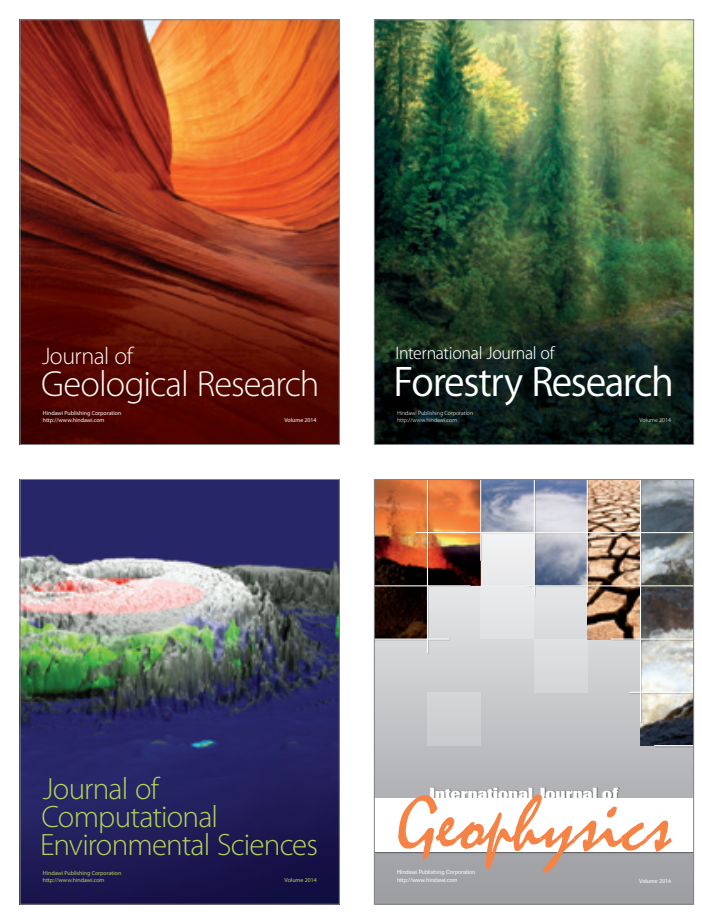
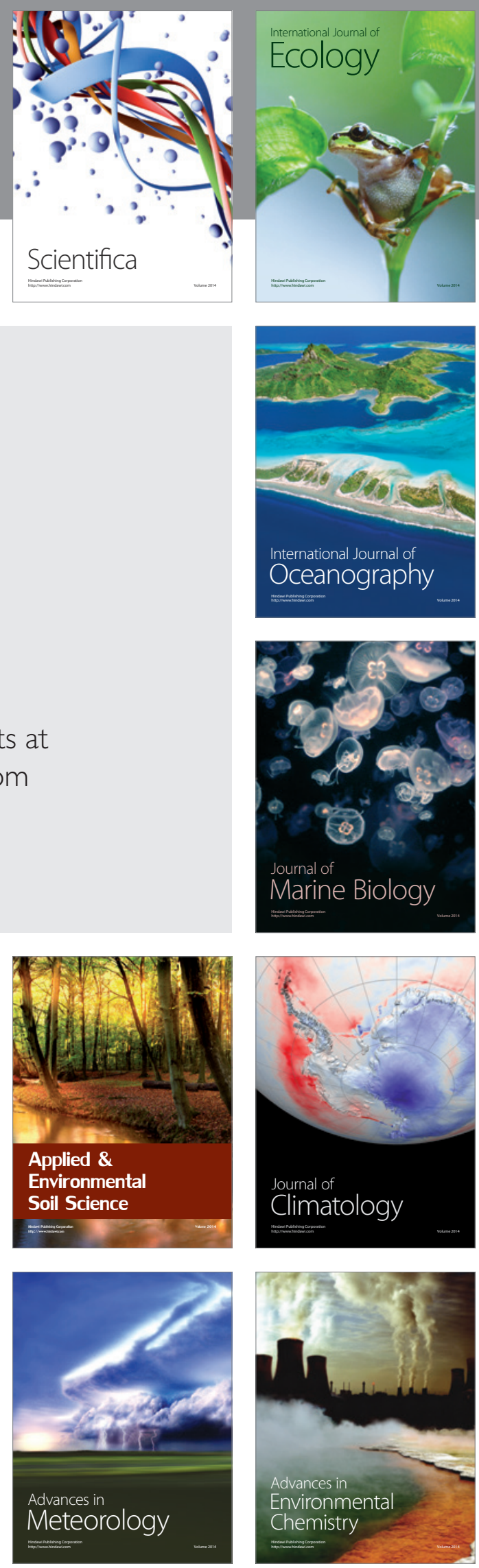